\title{
PERANCANGAN DAN PEMBUATAN LAMPU DARURAT UNTUK DAERAH RAWAN BENCANA ALAM
}

\author{
Oleh : Rony Haendra Rahwanto Fora *)
}

\begin{abstract}
Abstrak
Pembuatan lampu darurat sangat diperlukan karena kita harus mengantisipasi keadaan darurat misalnya padamnya lampu listrik. Kebutuhan penerangan yang dibutuhkan adalah penerangan sekitar 40 watt lampu tabung, namun pembuatan lampu darurat ini bisa memenuhi penerangan yang sama tetapi daya yang digunakan bisa sepertiganya. Selain dayanya bisa berkurang menjadi sepertiganya keuntungan lainnya adalah bentuknya kecil sangat ringan dijinjing dan dari segi charge dayanya bisa dengan cara diputar secara manual sehingga tidak tergantung dari daya PLN yang tidak bisa kita andalkan saat terjadi bencana.
\end{abstract}

Kata Kunci : daya kecil, mudah dijinjing, charge manual

\section{PENDAHULUAN}

\section{A. Gambaran Umum}

Di daerah yang rawan bencana, apakah disebabkan oleh bencana banjir, gempa, tanah longsor, dan lain-lain, sering kali terjadi pemadaman listrik guna pengamanan. Untuk mengatasi permasalahan tersebut agar tidak terjadi tindakan kriminal, dan aktivitas kita untuk memenuhi kehidupan di malam hari tidak terganggu akibat tidak adanya penerangan. Maka diperlukan suatu alat penerangan darurat.

Saat ini banyak dijual alat penerangan darurat atau lampu darurat (emergency lamp) yang dapat digunakan bila suplai listrik dari PLN padam. System kerjanya menggunakan aki ataupun baterai. Kemampuan lampu ini untuk memberikan penerangan terbatas pada kemampuan atau kapasitas aki atau baterai. Ada yang mampu bertahan 1 jam, 2 jam, dan ada yang maksimum sampai 4 jam. Lalu apa yang terjadi setelah lampu ini padam karena tegangan pada aki atau baterai telah habis? Maka kita hanya mengharapkan agar listrik lekas menyala sehingga lampu bias kembali menerangi. Kemudian, bila listrik padam sampai berhari-hari bagaimana?

Untuk alternatif masalah tersebut diatas ialah dengan cara menggunakan pembangkit listrik secara mandiri sehingga tidak bergantung pada PLN. Misalnya menggunakan generator set (genset) yang harganya relatif mahal dan membutuhkan bahan bakar yang susah didapatkan pada saat terjadi bencana. Oleh karena itu dibutuhkan lampu darurat yang tidak memerlukan bahan bakar minyak. Dalam usulan proposal ini, akan diuraikan perancangan dan pembuatan lampu darurat yang dilengkapi alat pengisi baterai secara manual. Sehingga lampu darurat ini bisa menyala lebih lama tanpa takut baterai akan habis.

\section{B. Potret Lokasi Bencana}

Bencana alam datang secara tibatiba dan tidak bisa kita prediksi. Sebagai contoh pada saat musim hujan seperti yang terjadi sekarang, sering menimbulkan banjir di daerah-daerah aliran sungai.

Satu contoh, akibat meluapnya kali Lamong yang menyebabkan terendamnya ribuan rumah warga di Kecamatan Benjeng, Kabupaten Gresik, Jawa Timur, merupakan bencana rutin tahunan yang membuat masyarakat resah. Ironisnya, masyarakat tetap memilih bertahan di lokasi banjir walaupun genangan mencapai ketinggian 80 cm (bahkan lebih). Dan karakter banjir di daerah ini bisa datang ketika tidak ada hujan di daerah itu. Hal ini terjadi akibat tingginya curah hujan di bagian hulu kali Lamong, namun luapannya melanda daerah Benjeng. Rentang waktu datangnya banjir cukup lama, yaitu sejak bulan Nopember hingga Maret, dengan durasi sekitar 4 hari genangan tiap banjir dengan frekuensi dalam satu bulan bisa dua, bahkan tiga kali kejadian. Dari 23 Desa di wilayah Kecamatan Benjeng, terdapat 14 wilayah Desa yang merupakan langganan banjir, baik kiriman maupun luapan saat hujan tiba. Empat Desa yang paling parah ialah :

\footnotetext{
*) Dosen Teknik Elektro

Universitas PGRI Adi Buana Surabaya
} 
Kedungrukem, Sirnoboyo, Delik Sumber, dan Sedapur Klagen, dengan kondisi rumah terendam berturut-turut sebanyak : 415,325 , 205, dan 139 dengan ketinggian rata-rata antara $50-80 \mathrm{~cm}$.

Mengacu dari data diatas, maka rencana penerapan IPTEKS ini akan dilakukan di Desa Sedapur Klagen yang merupakan area paling parah terkena dampak banjir, baik dari jumlah rumah terendam maupun ketinggiannya. Teknologi yang akan diterapkan adalah : Perancangan Dan Pembuatan Lampu Darurat Untuk Daerah Rawan Bencana Alam

\section{Perumusan Masalah}

Rumusan masalah dalam penerapan

IPTEKS ini adalah :

Mengatasi pemadaman listrik bagi masyarakat yang digunakan untuk alat penerangan khususnya pada malam hari menggunakan teknologi tepat guna (TTG) berupa alat penerangan lampu darurat (emergency lamp).

\section{Batasan - batasan}

1. Definisi :

Generator : pembangkit tegangan listrik yang akan digunakan untuk pengisian baterai.

Rangkaian pengisi (charger) : rangkaian elektronika yang berfungsi sebagai penyearah tegangan dari AC menjadi DC untuk proses pengisian baterai.

Baterai : jenis elemen kering yang digunakan untuk menyimpan tegangan dan memberikan tegangan pada lampu.

Indikator baterai: rangkaian elektronika yang berfungsi sebagai indikator atau tanda yang menginformasikan tentang kapasitas baterai untuk mengetahui kondisi tegangannya. Sehingga mengetahui saat harus diisi dan saat sudah penuh. Lampuled : jenis lampu yang
digunakan.

2. Asumsi :

1) Pengoperasian teknologi tepat guna (TTG) ini sangat efektif dan mudah dalam penggunaannya.

2) Dengan adanya TTG berupa lampu darurat ini, masyarakat terbantu dalam hal alat penerangan khususnya di malam hari, karena kondisi aliran listrik dari PLN padam.

Lingkup penerapan IPTEKS :

Kelompok Karang Taruna, Perangkat Desa, dan Kepala keluarga warga masyarakat Desa Sedapur Klagen Kecamatan Benjeng
Kabupaten Gresik Provinsi JATIM yang merupakan Desa rawan banjir di daerah itu.

\section{E. Tujuan dan Manfaat}

Tujuan dari penerapan IPTEKS ini adalah :

c. Memberikan pengetahuan kepada masyarakat tentang manfaat lampu darurat baik cara pengoperasian maupun cara perawatannya. Karena saat terjadi banjir, aliran listrik padam sehingga membutuhkan alat penerangan alternatif

d. Melatih warga masyarakat atau pemuda Karang Taruna yang mempunyai kemampuan atau pengetahuan tentang elektronika dan kelistrikan, untuk dapat merakit sendiri teknologi tepat guna berupa lampu darurat yang efektif digunakan pada daerah rawan listrik padam yang lamanya berhari-hari.

Manfaat dari penerapan IPTEKS ini adalah :

a. Untuk membantu mengatasi masalah kebutuhan lampu penerangan khususnya di malam hari akibat dari padamnya aliran listrik PLN.

b. Masyarakat mengetahui tentang alat penerangan alternatif berupa lampu darurat serta cara pembuatannya. Sehingga diharapkan dapat membuat atau merakit sendiri alat yang dimaksud.

\section{F. Sasaran}

Sasaran penerapan IPTEKS adalah warga masyarakat Desa Sedapur Klagen Kecamatan Benjeng Kabupaten Gresik Provinsi JATIM yang merupakan Desa rawan banjir, dan aliran listrik yang padam. Dengan kriteria kelompok sebagai berikut :

a. Karang Taruna

Sumber daya manusia yang produktif dalam penerapan IPTEKS ini.

b. Perangkat Desa

Institusi terkait dalam pendampingan warga saat bencana.

c. Kepala keluarga

Sebagai orang yang bertanggung jawab atas keluarganya juga dalam hal pemenuhan alat penerangan, sehingga membantu aktifitas kehidupan keluarganya.

\section{TINJAUAN PUSTAKA}

Alat penerangan sangat dibutuhkan saat kondisi gelap. Penyebabnya antara lain ialah padamnya aliran listrik yang disuplai oleh PLN. Sebagai alat penerangan alternatif, digunakan lampu yang didayai oleh baterai 
atau aki yang umumnya dikenal sebagai lampu darurat.

Sistem kerja lampu ini ialah berupa lampu ( jenis neon, dop, led ) yang sumber tegangannya berasal dari baterai atau aki. Jenis / type, ukuran, merk dari lampu darurat yang dijual dipasaran bermacam-macam. Lampu darurat ini mempunyai kapasitas atau kemampuan yang umunya diukur dari lamanya waktu kerja. Kapasitas lampu darurat pada umumnya mampu bertahan antara $1-4$ jam. Selanjutnya maka baterai atau aki harus diisi lagi (charge) agar bisa digunakan kembali. Untuk melakukan pengisian baterai atau aki umumnya menggunakan sumber tegangan dari PLN.

Pada saat terjadi banjir, aliran listrik bisa padam cukup lama bahkan sampai beberapa hari. Sehingga untuk melakukan pengisian ulang lampu darurat harus menunggu sampai aliran listrik menyala kembali. Untuk mengatasi hal tersebut, pengusul membuat sebuah alat berupa lampu darurat yang dapat melakukan pengisian ulang (recharge) baterai secara manual. Yakni dengan menambahkan sebuah generator yang kerjanya diputar oleh tangan kita saat melakukan pengisian ulang. Sehingga lampu darurat ini efektif saat digunakan untuk jangka waktu yang lama.

Mengacu dari dasar teoritis dan fakta hasil penelitian di lapangan, maka kerangka penerapan IPTEKS ini didasari dari beberapa hal :
a. Generator
b. Penyearah tegangan
c. Baterai
d. Lampu

\section{a. Generator}

Jenis generator ada dua, yakni generator AC dan generator DC.

1. Generator AC

Bagian utama generator $A C$ terdiri atas magnet permanen (tetap), kumparan (solenoida), cincin geser, dan sikat. Pada generator, perubahan garis gaya magnet diperoleh dengan cara memutar kumparan di dalam medan magnet permanen. Karena dihubungkan dengan cincin geser, perputaran kumparan menimbulkan GGL induksi AC. Oleh karena itu, arus induksi yang ditimbulkan berupa arus AC. Adanya arus AC ini ditunjukkan oleh menyalanya lampu pijar yang disusun seri dengan kedua sikat. Sebagaimana percobaan Faraday, GGL induksi yang ditimbulkan oleh generator AC dapat diperbesar dengan cara:
1. Memperbanyak lilitan kumparan,

2. Menggunakan magnet permanen yang lebih kuat.

3. Mempercepat perputaran kumparan, dan menyisipkan inti besi lunak ke dalam kumparan.

Contoh generator AC yang akan sering kita jumpai dalam kehidupan sehari-hari adalah dinamo sepeda. Bagian utama dinamo sepeda adalah sebuah magnet tetap dan kumparan yang disisipi besi lunak. Jika magnet tetap diputar, perputaran tersebut menimbulkan GGL induksi pada kumparan. Jika sebuah lampu pijar (lampu sepeda) dipasang pada kabel yang menghubungkan kedua ujung kumparan. lampu tersebut akan dilalui arus induksi AC. Akibatnya, lampu tersebut menyala. Nyala lampu akan makin terang jika perputaran magnet tetap makin cepat (laju sepeda makin kencang).

\section{Generator DC}

Prinsip kerja generator (dinamo) DC sama dengan generator AC. Namun, pada generator DC arah arus induksinya tidak berubah. Hal ini disebabkan cincin yang digunakan pada generator DC berupa cincin belah (komutator).

Pada pembuatan lampu darurat ini, pengusul memakai generator dari dinamo sepeda yang mempunyai kapasitas 12V / 6 Watt. Sehingga laju arus sebesar $500 \mathrm{~mA}$.

\section{b. Penyearah tegangan}

Terdiri dari rangkaian elektronika yang berfungsi untuk menyearahkan tegangan yang dihasilkan oleh generator $\mathrm{AC}$, merubah tegangan bolak-balik menjadi tegangan searah (DC) yang digunakan untuk mengisi ulang baterai. Rangkaian ini terdiri dari 4 buah diode yang disusun jembatan (bridge). Besar tegangan yang disearahkan ialah $12 \mathrm{~V}$ dan 500mA. Dari keluaran tegangan ini langsung disambung dengan baterai yang disusun seri.

\section{Pengisi Baterai NiCad}

Tiap baterai NiCad mempunyai tegangan 1.2 volt lebih rendah 0.3 volt jika dibandingkan dengan baterai biasa atau baterai alkaline. Sebuah pengisi baterai NiCad yang baik harus mempunyai spesifikasi antara lain : 


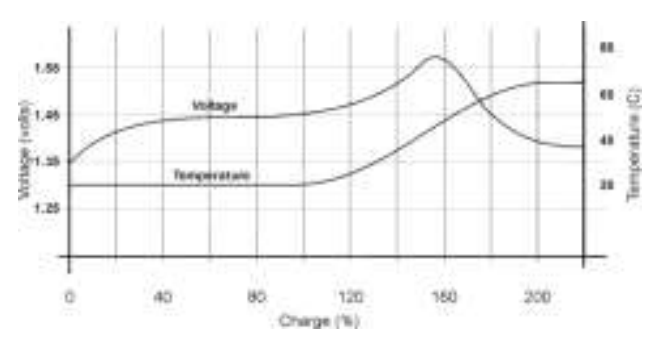

Gambar 1. Karakteristik Pengisian Baterai $\mathrm{NiCad}$

1. Autoshut-off, merupakan kemampuan charger untuk menghentikan arus pengisian ke sebuah baterai NiCad jika kapasitas baterai NiCad sudah terisi penuh.

2. Polarity Protection, dengan adanya kemampuan ini maka jika terdapat pemasangan baterai yan terbalik pada charger dapat diketahui.

3. Tegangan output konstan

4. Arus output cukup untuk mengisi beberapa baterai NiCad sekaligus secara paralel.

5. Short Circuit Protection, dengan adanya rangkaian proteksi ini maka jika terjadi hubungan singkat yang ditimbulkan oleh baterai maupun rangkaian charger sendiri tidak akan merusak bagian yang lain yang tidak rusak.

Sebuah charger paling tidak harus mempunyai tegangan output diatas 1.5 volt dan mampu memberikan arus charge paling tidak $1 / 10$ arus output baterai. Jika tiap baterai NiCad dapat mensuplai arus sebesar $700 \mathrm{mAH}$ maka baterai NiCad ini harus diisi dengan arus dibawah $70 \mathrm{~mA}$. Rating arus pengisian ini, $1 / 10$ arus output baterai merupakan batasan maksium untuk sebuah baterai NiCad. Semakin besar arus pengisiannya maka baterai akan semakin cepat terisi namun suhu baterai akan dengan cepat pula naik. Suhu baterai yang terlalu tinggi dapat menyebabkan baterai NiCad ini rusak atau bahkan meledak.

Dari gambar 1 dapat dilihat bahwa tegangan pengisian akan berpengaruh pada suhu baterai. Baterai NiCad yang terusmenerus diisi namun muatannya belum habis akan memperpendek umur dari baterai itu sendiri. Inilah yang disebut dengan efek memory. Apabila baterai NiCad sudah mengalami efek memory maka baterai tersebut masih dapat diisi penuh namun lebih cepat habis jika dibandingkan dengan baterai NiCad yang masih baru. Kondisi ini tidak dapat diperbaiki karena menyangkut rekasi kimiawi di dalam baterai $\mathrm{NiCad}$ tersebut. Oleh karena itu sebuah charger yang baik harus dilengkapi dengan kemampuan autoshut off jika baterai $\mathrm{NiCad}$ yang diisi sudah penuh.

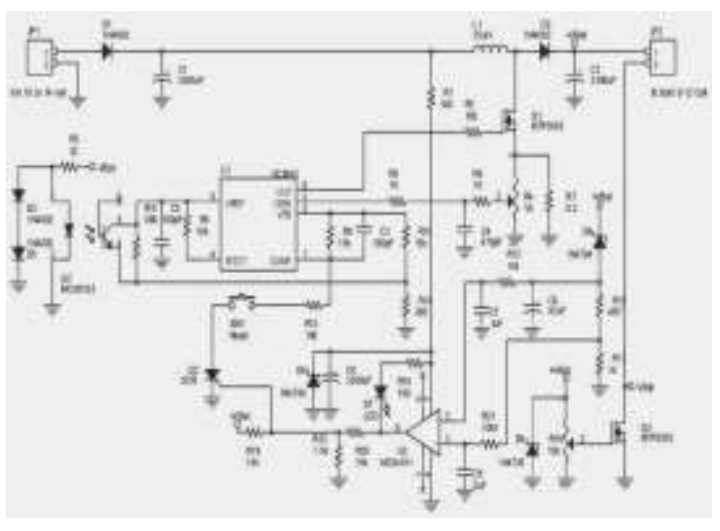

Gambar 2. Skematik Rangkaian Ultra Fast Charger

Komponen utama pada rangkaian ini adalah UC3843 dan MC34181. UC3843 merupakan chip regulator tegangan dan M34181 merupakan OpAmp JFET dengan karakteristik low offset voltage, impedansi input yang sangat tinggi. MC34181 berfungsi sebagai voltage komparator.

\section{Karakteristik Baterai Nickel Cadmium}

Sebuah pengisi baterai $\mathrm{NiCad}$ harus mempunyai karakteristik yang disesuaikan dengan baterai yang di-charge. Karakteristik baterai NICad antara lain:

2. Baterai NiCad harus diisi dengan besar arus yang konstan.

3. Baterai akan penuh terisi jika mencapai $140 \%$ pengisian dari pengisian maksimum baterai tersebut.

4. Variasi perubahan tegangan baterai tergantung dari fungsi pengisian dan juga tergantung dari suhu baterai tersebut.

5. Pada saat pengisian telah selesai maka suhu akan naik dengan cepat (panas meningkat dengan cepat) sehingga chager perlu dimatikan. Karena jika tidak dimatikan akan dapat menyebabkan suhu baterai akan naik terus dan pada akhirnya akan meledak.

Sehingga paling tidak untuk membuat sebuah pengisi baterai NiCad yang perlu diperhatikan adalah :

1. Besar arus pengisian yang konstan

2. Menggunakan SwitchMode Converter untuk menaikkan tegangan output 
charger jika tegangan baterai yang dicharge di atas 10 volt.

3. Pengamanan rangkaian. Rangkaian pengamanan pada rangkaian biasanya menggunakan pengaman arus dan pengaman autoshut off.

Pada gambar 2 merupakan gambar skematik rangkaian untuk ultra fast charger. Charger tersebut dapat digunakan untul 8 sampai 10 baterai NiCad sekaligus dengan tegangan output 12 volt dan arus maksium adalah $3.5 \mathrm{~A}$

\section{Cara Kerja Rangkaian}

Pada rangkaian pada gambar 2 ada 3 bagian utama yaitu :

1. Regulator Arus.

2. Konverter SwitchMode

3. Rangkaian Pendeteksi/Pengaman.

\section{Regulator Arus Konstan}

Rangkaian regulator ini menggunakan MTP3055, TMOS Power MOSFET yang mempunyai berbagai operasi kerja dengan mengatur besar/kecil arus pengisian ke baterai NiCad. Arus pengisian ini pada dasarnya tidak tergantung dari tegangan Drain Source (VDS) ketika tegangan VDS melebihi 2 volt.

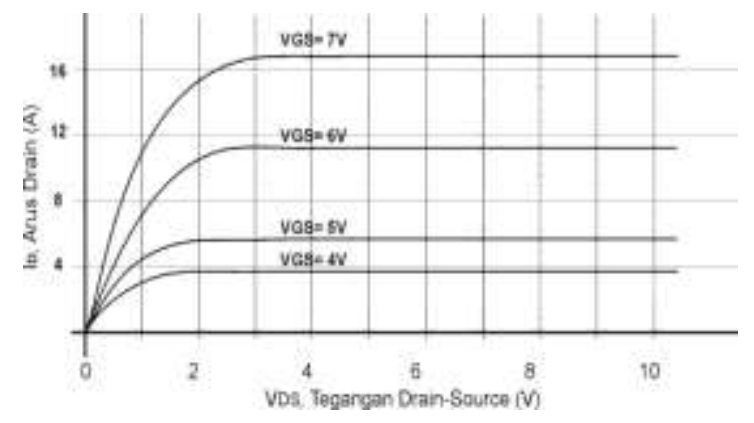

Gambar 3. Karakteristik MOSFET MTP3055

Jadi jika tegangan VDS lebih dari 2 volt maka arus ID akan juga konstan.

\section{Konverter Switch Mode}

Rangkaian konverter DC to DC tetap digunakan untuk membuat tegangan output sampai $12 \mathrm{~V}$ walaupun tegangan input hanya 10 volt. Untuk itu digunakan UC3843 dengan frekuensi kerja sampai $100 \mathrm{KHz}$. Dengan menggunakan induktor $25 \mathrm{uH}$ akan didapatkan tegangan yang sangat stabil.

Optocoupler MOC8102 digunakan untuk memonitor tegangan yang masuk ke regulator dan memberikan informasi error atau tidak ke pin error amplifier pada UC3843. Ketika terjadi penurunan tegangan maka UC3843 akan menstabilkan tegangan VDS pada tegangan kira-kira 2 volt shingga disipasi daya nutuk mosfet ini sebesar 7 Watt.

Thyristor 2N5061 digunakan untuk membatasi tegangan jika terjadi kelebihan tegangan sampai pada 40 volt. Jika terjadi over voltage maka thyristor ini akan cut off dan mematikan operasi charger ini.

\section{Rangkaian Sistem Deteksi}

Kontrol dan Shutoff pada pengisian penuh diatur oleh MC34181 dan thyristor 2N5061. Ketika tegangan baterai yang sedang diisi telah menandakan penuh maka tegangan pada input non-inverting akan memaksa output MC34181 toggle sehingga akan mematikan LED. Pada saat pengisian LED akan menyala. Diode D2 digunakan untuk melindungi baterai dari polaritas tegangan baterai yang terbalik. Jika output charger terjadi 'short circuit' maka arus tetap diatur konstan tetapi regulator akan menjadi panas. Sehingga kondisi 'short circuit' tidak boleh terjadi terlalu lama.

\section{c. Baterai}

Baterai saat ini masih menjadi sumber tenaga alternatif yang masih sering digunakan untuk berbagai aplikasi seperti untuk radio saku (pocket radio), MP3man, discman dan aplikasi lain yang sering digunakan untuk traveling. Bagi beberapa orang baterai bukanlah menjadi masalah tetapi jika aplikasi yang menggunakan betari tersebut ternyata menggunakan daya yang besar maka tentu saja baterai yang digunakan juga banyak. Sehingga dapat dipastikan biaya untuk baterai juga membengkak.

Misalnya kita bandingkan penggunaan baterai untuk discman dan lampu blitz. Jumlah baterai yang digunakan tentu lebih banyak untuk lampu blitz dan daya tahan baterainya lebih pendek daripada daya tahan baterai yang digunakan untuk discman. Dengan kata lain baterai cenderung digunakan untuk perlatan elektronika yang menggunakan daya kecil dan peralatan yang mudah dibawa-bawa (portable).

Sebagai alternatif adalah menggunakan adaptor atau power supplay eksternal tetapi dengan kekurangan yaitu tidak dapat digunakan untuk travelling. Solusi yang paling tepat adalah menggunakan baterai yang dapat diisi ulang. 
Kelebihan dari baterai ini adalah tempat yang digunakan sama dengan tempat yang digunakan pada baterai biasa sehingga tidak perlu memodifikasi casing-nya. Selain itu jika dibandingkan dengan baterai biasa, baterai nickel cadmium atau yang lebih dikenal sebagai Baterai NiCad ini, mempunyai daya tahan sedikit di atas baterai biasa (dengan catatan kondisi baterai NiCad ini masih baik).

Baterai NiCad yang ada dipasaran saat ini ada dua pilihan untuk ukuran dayanya, yaitu $700 \mathrm{mAH}$ atau $1500 \mathrm{mAH}$. Maksudnya adalah baterai NiCad tersebut dapat mensuplai arus ke peralatan elektronika dengan arus $700 \mathrm{~mA}$ selama 1 jam (untuk baterai $700 \mathrm{mAH}$ ). Sehingga jika kita menggunakan baterai NiCAD $700 \mathrm{mAH}$ tersebut untuk peralatan elektronika yang menarik arus sebesar $1 \mathrm{~A}$ maka baterai NiCad tersebut hanya dapat bertahan selama kurang dari 1 jam. Suhu dari baterai NiCad juga mempengaruhi daya tahan baterai. Jika baterai terlalu panas maka baterai akan cepat habis karena sebagaian arus yang dihasilkan oleh baterai tersebut diubah menjadi panas.

Karena baterai NiCad bisa diisi ulang untuk beberapa kali (puluhan kali) maka baterai NiCad ini lebih murah dari pada baterai biasa. Namun dana yang digunakan utuk membeli baterai pertama kali memang lebih mahal dari pada membeli baterai biasa.

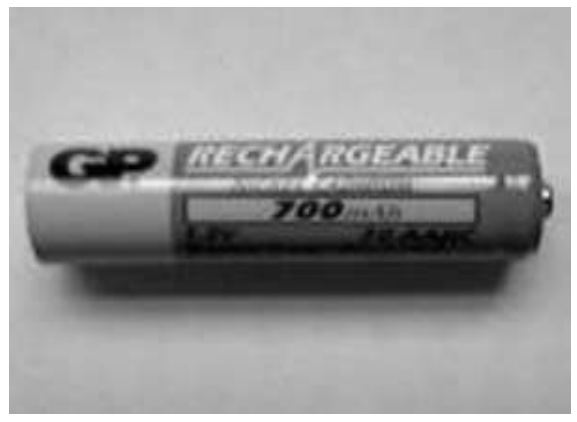

Gambar 4. Baterai jenis NiCad 700mAh

\section{d. Lampu}

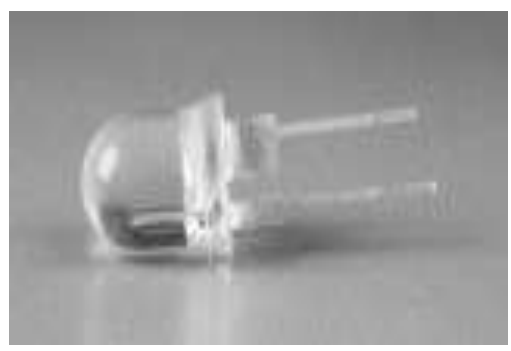

Gambar 5. Led putih super terang

Spesifikasi :

$$
\begin{array}{ll}
\text { Ukuran } & : 10 \times 13.65 \mathrm{~mm} \\
\text { Arus } & : 20 \mathrm{~mA} \\
\text { Tegangan } & : 3.2-3.6 \mathrm{~V}
\end{array}
$$

Pada lampu darurat yang dirancang ini memakai lampu jenis led yang disusun secara seri dan paralel sebanyak 30 buah led sehingga total nyala lampu \pm 1.100 lux. Disusun menjadi 3 bagian, masing-masing terdiri dari 10 led. Untuk penghitungan arus dan tegangan yang digunakan ialah :

$$
\begin{aligned}
& 20 \mathrm{~mA} \times 2=40 \mathrm{~mA} \\
& 3.2 \mathrm{~V} \times 2=6.4 \mathrm{~V}
\end{aligned}
$$

\section{e. Perancangan alat}

Perancangan lampu darurat ini dibuat sederhana dan mudah dalam pengoperasiannya. Serta bentuknya disesuaikan agar mudah dibawa kemanamana. Gambar rancangan alatnya sebagai berikut :

\section{SIMPULAN}

Dari kegiatan penelitian pengabdian masyarakat perancangan lampu darurat di daerah rawan bencana di dapatkan hasil sebagai berikut :

1. Hasil produksi lampu darurat yang mempunyai daya sangat kecil, peralatan mudah dibawa dan pengisian baterai yang tidak bergantung suplai daya dari PLN.

2. Hasil produksi lampu darurat yang mudah dibuat ulang oleh masyarakat pengguna sebagai sasaran dari penelitian ini.

3. Transfer / alih teknologi pembuatan lampu darurat kepada masyarakat pengguna bisa meningkatkan pengetahuan dan keterampilan teknologi tepat guna kepada masyarakat 


\section{DAFTAR PUSTAKA}

Americal Wind Energy Association at www.awea.com

Bergey Wind Power at www.bergey.com

Canadian Renewable Energy at www.re-energy.ca

C.-C. Lee,"A self-learning rule-based controller employing approximate reasoning and neural net concepts," Int.J.Intelegent Systems, vol.5,no.3, h.71-93,1991

D.E.Rumelhart,G.E.Hinton, dan R.J. Williams,"Learning internal representations by error propagation," in Parallel Distributed Processing: Explorations in the Microstructure of Cognition, D.E. Rumelhart dan James L. McClelland, Eds., vol. 1. Cambridge, MA: MIT Press, 1986, ch.8, h.318-362.

Gipe, P., 1999, Wind Energy Basics, A Guide to Small and Micro Wind Turbine, Chelsea Green Publishing Company.

W.T. Miller III, R.S. Sutton, dan P.J. Werbos, Eds., Neural Networks for Control. Cambridge, MA: MIT Press, 1990.

William J. Palm III, 1994, "Introduction to MATLAB for Engineers", Addison Wesley. 